\title{
Power Quality Improvement in DFIG based Wind Energy Conversion System using UPFC
}

\author{
M. Rama Sekhara Reddy ${ }^{1}$, Dr. M. Vijaya Kumar ${ }^{2}$ \\ ${ }^{1}$ Assistant Professor, Department of EEE, JNTUACE.Anantapur, A.P, India \\ ${ }^{2}$ Professor, Department of EEE, JNTUACE.Anantapur, A.P, India
}

\begin{abstract}
The wind energy generation, utilization and its grid penetration in electrical grid are increasing worldwide. The wind generated power is always fluctuating due to its time varying nature and causing stability problem. Unified Power Flow Controller (UPFC) is used to control the power flow in the transmission systems by controlling the impedance, voltage magnitude and phase angle. This controller offers advantages in terms of static and dynamic operation of the power system. A Unified Power Flow Controller (UPFC) is an electrical device for providing fast-sensation on high-voltage electricity transmission networks. UPFC uses a pair of threephase controllable bridges to produce current that is injected into a transmission line using a series transformer. The controller can control active and reactive power flows in a transmission line. The UPFC is a combination of a static synchronous compensator (STATCOM) and a static synchronous series compensator (SSSC) coupled via a common DC voltage link. The main scope of this paper involves in simulation of DFIG based wind energy conversion system with UPFC using MATLAB/ SIMULINK.
\end{abstract}

Keywords: DFIG, UPFC, FACTS, Power quality, THD, Harmonics, STATCOM, SSSC.

\section{INTRODUCTION}

In recent years, wind energy has become one of the most important and promising sources of renewable energy, which demands additional transmission capacity and better means of maintaining system reliability. The need to integrate the renewable energy like wind energy into power system is to make it possible to minimize the environmental impacts. Wind energy conversion systems are the fastest growing renewable source of electrical energy [1] having tremendous environmental and social benefits. To increase the system efficiency, high efficiency devices based on power electronics equipments have been increasingly used in many applications. This causes increasing harmonic levels on power systems and concerns about the future impact on system capabilities. So, if there is any fault in the subsystems there will be disturbances, disruptions and the other effects, which decrease the power quality in the system.

The power-transfer capability of long transmission lines are usually limited by large signals ability. Economic factors, such as the high cost of long lines and revenue from the delivery of additional power, give strong incentives to explore all economically and technically feasible means of raising the stability limit. On the other hand, the development of effective ways to use transmission systems at their maximum thermal capability has caught much research attention in recent years. Fast progression in the field of power electronics has already started to influence the power industry. The ability to control power flow in an electric power system without generation rescheduling or topology changes can improve performance using the power system performance using controllable components. Flexible ac transmission systems (FACTS) technology is the ultimate tool for getting the most out of existing equipment via faster control action and new capabilities. The most striking feature is the ability to directly control transmission line flows by structurally changing parameters of the grid and to implement high-gain type controllers based on fast switching.

The application of FACTS devices to power system security has been an attractive ongoing area of research. In most of the reported studies attention has been focused on the ability of these devices to improve the power system security by damping system oscillations and minimal attempts have been made to investigate the effect of these devices on power system reliability. The opportunities arise through the ability of FACTS controllers to control the interrelated parameters that governs the operation of transmission systems including series impedance and shunt impedance, current, phase angle and damping of oscillations at various frequencies below the rated frequency. These constraints cannot be overcome otherwise, while maintaining the required system stability, by mechanical means without lowering the useable transmission capacity. By providing added flexibility, FACTS controller can enable a line to carry power closer to its thermal rating. Mechanical switching needs to be supplemented by rapid-response power electronics. The FACTS technology can certainly be used to overcome any to the stability limits, in which case the ultimate limits would be thermal and dielectric.

The UPFC is recently introduced FACTS controller which has the capability to control all the four transmission parameters. The unified power-flow controller (UPFC) is a member of the FACTS family 
with very attractive features. This device can independently control many parameter, so it is the combination of the properties of a static synchronous compensator (STATCOM) and static synchronous series compensator (SSSC).

\section{POWER QUALITY}

The common concerns of power quality are long duration voltage variations (overvoltage, under voltage, and sustained interruptions), short duration voltage variations (interruption, sags (dips), and swells), voltage imbalance, waveform distortion (DC offset, harmonics, interharmonics, notching and noise), voltage fluctuation (voltage flicker) and power frequency variations. Most reasons of these concerns stems from loads connected to electric supply systems.

There are two types of loads, linear and nonlinear. Motors, heaters and incandescent lamps are examples of linear load produce a current proportional to the voltage. The nonlinear load uses high-speed electronic power switching devices to convert the AC supply voltage to a constant DC voltage used by the internal circuits. During converting, harmonic currents on the power grid are generated. Producing harmonic currents at the point of common coupling (PCC) cause several adverse effects such as a line voltage distortion at PCC, equipment overheating, transformer derating, overheating, failure of sensitive electronic equipment, interference with telecommunication systems due to harmonic noises, flickering of fluorescent lights, erratic operation of circuit breakers and relays, fuse blowing and electronic equipment shutting down, conductor overheating due to triplen harmonics in 3-phase 4- wire system, increased RMS current. Personal computers, fax machines, printers, UPS, adjustable speed drives, electronic lighting ballasts, ferromagnetic devices, DC motor drives and arcing equipment are examples of nonlinear loads.

\section{Power Quality Issues and Its Consequences:-}

Power quality problem [2] is any power problem manifested in voltage, current, or frequency deviation that results in failure or malfunctioning of customer equipment. Power quality is a two-pronged issue, with electronic equipment playing both villain and victim. Most new electronic equipment, while more efficient than its mechanical predecessors, consumes electricity differently than traditional mechanical appliances.

Power supply quality issues [3] and resulting problems are consequences of the increasing use of solid state switching devices, nonlinear and power electronically switched loads, electronic type loads the advent and wide spread of high power semiconductor switches at utilization, distribution and transmission leaves have non sinusoidal currents.

Power quality can be simply defined as shown in the interaction diagram:

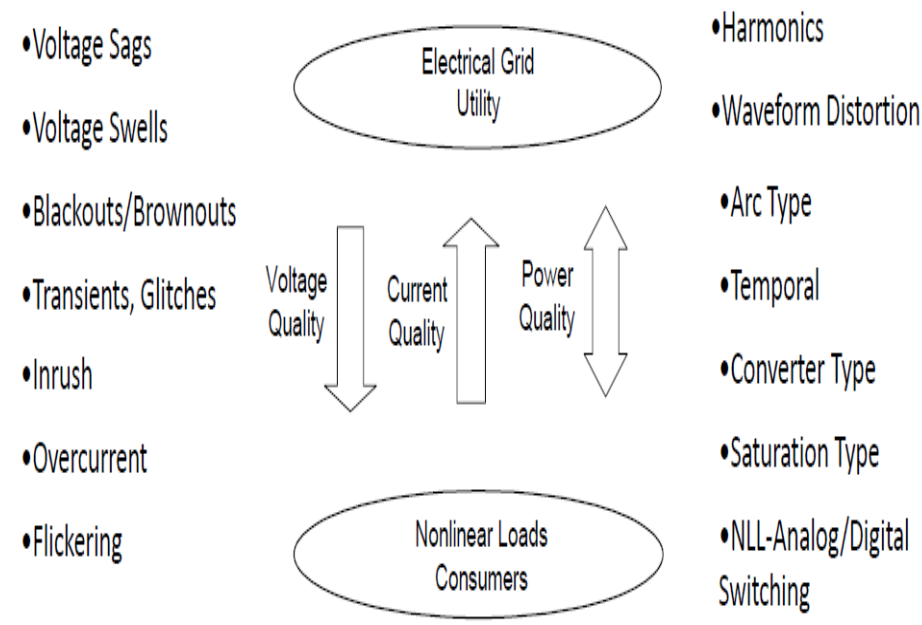

\section{Causes and consequences:}

The causes and consequences of power quality problems [4] can be traced to a specific type of electrical disturbance. In most of industry, more than $90 \%$ of the electric motor with inverter driven application.Poor power quality causes trouble in receptacle/transmission equipment and electronic equipment malfunctions / Failure. Power quality is a common problem for both electric power suppliers and users. It is not easy to identify whether the cause of poor power supply quality [5] is at the supplier's system or the user's system. 
Power disturbances can be classified into the following categories.

- Interruptions/ Black-out/ Power outage

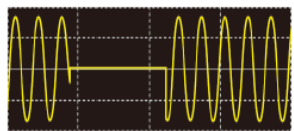

Voltage dips/ sags/ brown-out

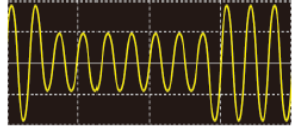

- Voltage surges/ swells

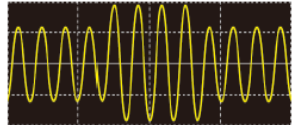

- Frequency variations

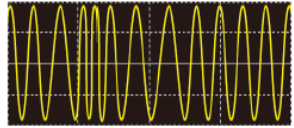

- Transients/ Bursts/ Voltage peaks

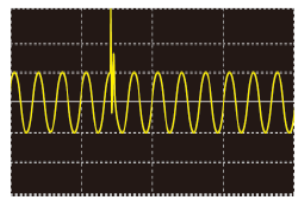

- Harmonics

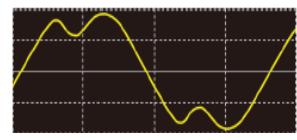

\section{$>$ Power outages:}

Power outages are total interruptions of electrical supply. Utilities have installed protection equipment that briefly interrupts power to allow time for a disturbance to dissipate.

- Causes: Ice storms; lightning; wind; utility equipment failure.

- Effects: Complete disruption of operation.

$>$ Voltage fluctuations:

Voltage fluctuations are changes or swings in the steady-state voltage above or below the designated input range for a piece of equipment. Fluctuations include both sags and swells.

- Causes: Large equipment start-up or shut down; sudden change in load.

- Effects: Data errors; memory loss; equipment shutdown; flickering lights; motors stalling/stopping.

$>$ Transients:

Transients, commonly called "surges," are sub-cycle disturbances of very short duration that vary greatly in magnitude. When transient occur, thousands of voltage can be generated into the electrical system, causing problems for equipment down the line.

- Causes: Lighting; equipment start-up and shutdown; welding equipment.

- Effects: Processing errors; computer lock-up; burned circuit boards; degradation of electrical insulation; equipment damage.

\section{> Harmonics:}

Harmonics are the periodic steady-state distortions of the sine wave due to equipments generating frequency other than the standard 60 cycles per second.

- Causes: Electronic ballasts; non-linear loads; variable frequency drives.

- Effects: Overheating of electrical equipment; random breakers tripping; hot neutrals.

\section{A Characteristics of UPFC:-}

\section{UNIFIED POWER FLOW CONTROLLER (UPFC)}

Line outage, congestion, cascading line tripping, power system stability loss are the major issues where capability and utilization of FACTS are noticed. Representative of the last generation of FACTS devices [6] is the Unified Power Flow Controller (UPFC). The UPFC is a device which can control simultaneously all three parameters of line power flow (line impedance, voltage and phase angle). Such "new" FACTS device combines together the features of two "old" FACTS devices: the Static Synchronous Compensator (STATCOM) [7] and the Static Synchronous Series Compensator (SSSC).

In practice, these two devices are two Voltage Source Inverters (VSI's) connected respectively in shunt with the transmission line through a shunt transformer and in series with the transmission line through a series transformer, connected to each other by a common dc link including a storage capacitor. The shunt inverter is used for voltage regulation at the point of connection injecting an opportune reactive power flow into 
the line and to balance the real power flow exchanged between the series inverter and the transmission line. The series inverter can be used to control the real and reactive line power flow inserting an opportune voltage with controllable magnitude and phase in series with the transmission line. Thereby, the UPFC can fulfill functions of reactive shunt compensation, active and reactive series compensation and phase shifting. Besides, the UPFC allows a secondary but important function such as stability control to suppress power system oscillations improving the transient stability of power system. As the need for flexible and fast power flow controllers, such as the UPFC, is expected to grow in the future due to the changes in the electricity markets, there is a corresponding need for reliable and realistic models of these controllers to investigate the impact of them on the performance of the power system. In this article emphasis is laid to project the use of UPFC in transmission link to increase the power flow and to improve the voltage profile of the system using MATLAB/ SIMULINK.

\section{B Operation of UPFC:-}

The basic components of the UPFC are two voltage source inverters (VSIs) sharing a common dc storage capacitor and connected to the power system through coupling transformers. One VSI is connected to in shunt to the transmission system via a shunt transformer, while the other one is connected in series through a series transformer. A basic UPFC functional scheme is shown in Fig..1.

\section{UPFC}

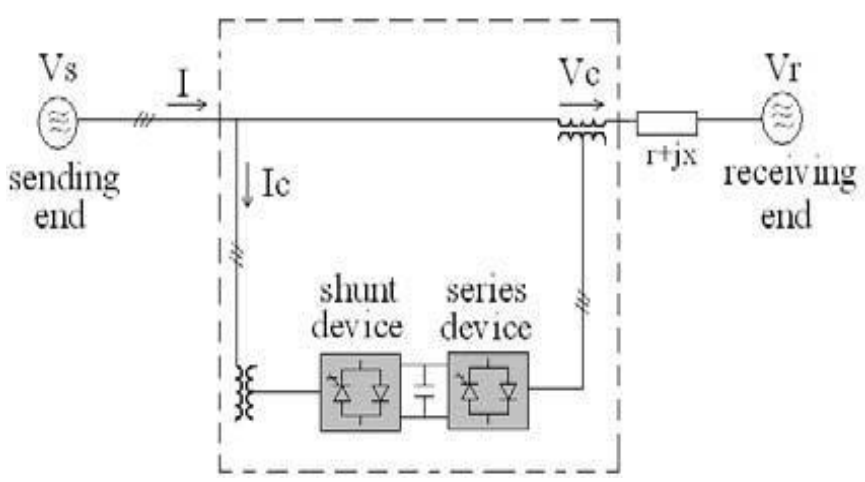

Fig 1 UPFC Link in Transmission Line

The series inverter is controlled to inject a symmetrical three phase voltage system (Vc), of controllable magnitude and phase angle in series with the line to control active and reactive power flows on the transmission line. So, this inverter will exchange active and reactive power with the line. The reactive power is electronically provided by the series inverter, and the active power is transmitted to the dc terminals.

The shunt inverter is operated in such a way as to demand this dc terminal power (positive or negative) from the line keeping the voltage across the storage capacitor Vdc constant. So, the net real power absorbed from the line by the UPFC is equal only to the losses of the inverters and their transformers. The remaining capacity of the shunt inverter can be used to exchange reactive power with the line so to provide a voltage regulation at the connection point. The two VSI's can work independently of each other by separating the dc side. So in that case, the shunt inverter is operating as a STATCOM (Static Synchronous Compensators) [8] that generates or absorbs reactive power to regulate the voltage magnitude at the connection point. Instead, the series inverter is operating as SSSC (Static Synchronous series compensators) that generates or absorbs reactive power to regulate the current flow, and hence the power flows on the transmission line.

\section{Operating Modes of UPFC:-}

The UPFC has many possible operating modes. In particular, the shunt inverter is operating in such a way to inject a controllable current, into the transmission line. This current consists of two components with respect to the line voltage: the real or direct component, which is in phase or in opposite phase with the line voltage, and the reactive or quadrature component, which is in quadrature. The direct component is automatically determined by the requirement to balance the real power of the series inverter. The quadrature component, instead, can be independently set to any desired reference level (inductive or capacitive) within the capability of the inverter, to absorb or generate respectively reactive power from the line.

\section{UPFC CONTROL SYSTEM}

The UPFC consists of two voltage source converters; series and shunt converter, which are connected to each other with a common dc link. Series converter or Static Synchronous Series Compensator (SSSC) [9] is used to add controlled voltage magnitude and phase angle in series with the line, while shunt converter or Static Synchronous Compensator (STATCOM) is used to provide reactive power to the ac system, beside that, it will 
provide the dc power required for both inverter. Each of the branches consists of a transformer and power electronic converter. These two voltage source converters shared a common dc capacitor.

The energy storing capacity of this dc capacitor is generally small. Therefore, active power drawn by the shunt converter should be equal to the active power generated by the series converter. The reactive power in the shunt or series converter can be chosen independently, giving greater flexibility to the power flow control. The coupling transformer is used to connect the device to the system. Fig. 2 shows the schematic diagram of the three phase UPFC connected to the transmission line.

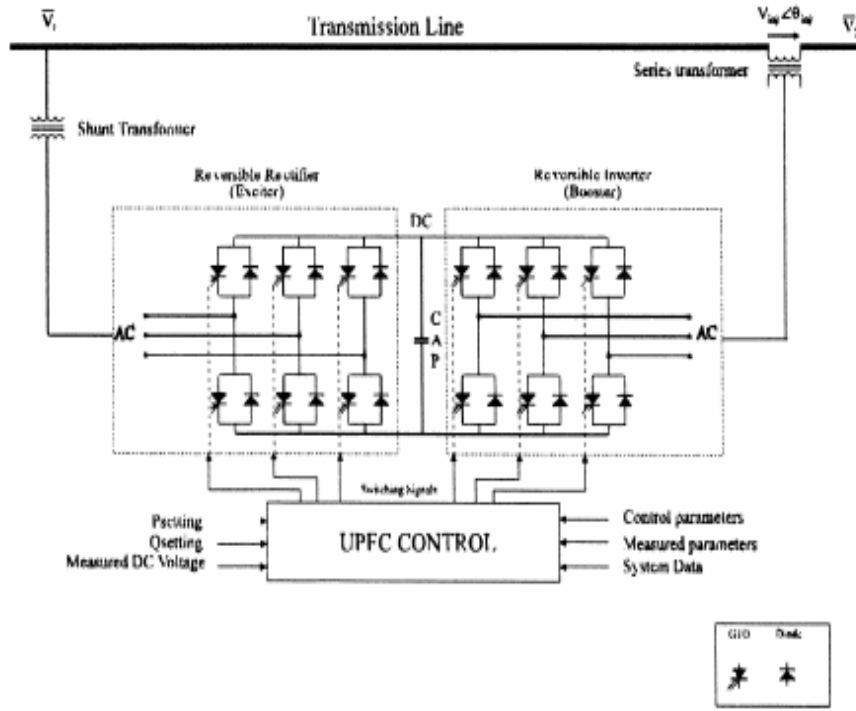

Fig.2 Schematic diagram of three phase UPFC connected to a transmission line

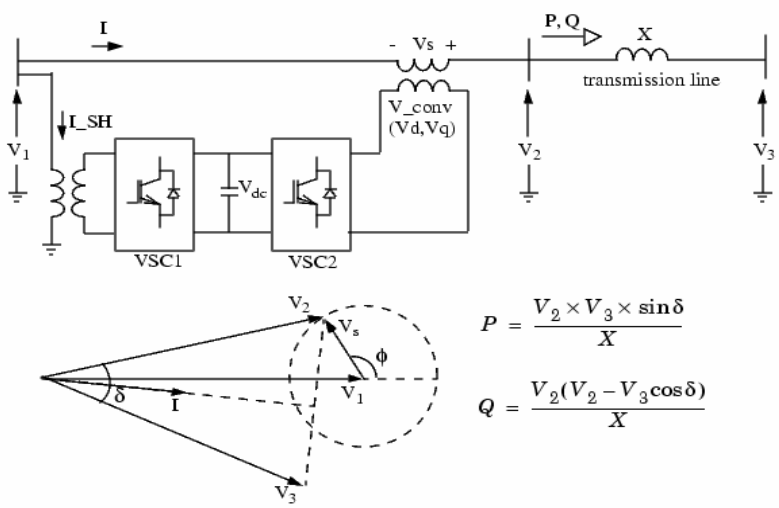

Fig.3 Single line diagram of UPFC and phasor diagram of voltage and current

Control of power flow is achieved by adding the series voltage, VS with a certain amplitude, $|\mathrm{VS}|$ and phase shift, $\phi$ to V1. This will gives a new line voltage V2 with different magnitude and phase shift. As the angle $\phi$ varies, the phase shift $\delta$ between V2 and V3 also varies. Fig. 3 shows the single line diagram of the UPFC and phasor diagram of voltage and current.

This FACTS topology provides much more flexibility than the SSSC for controlling the line active and reactive power because active power can now be transferred from the shunt converter to the series converter, through the DC bus. Contrary to the SSSC where the injected voltage Vs is constrained to stay in quadrature with line current I, the injected voltage Vs can now have any angle with respect to line current. If the magnitude of injected voltage Vs is kept constant and if its phase angle with respect to V1 is varied from 0 to 360 degrees, the locus described by the end of vector $\mathrm{V} 2(\mathrm{~V} 2=\mathrm{V} 1+\mathrm{Vs})$ is a circle as shown on the phasor diagram. As is varying, the phase shift $\delta$ between voltages $\mathrm{V} 2$ and $\mathrm{V} 3$ at the two line ends also varies. It follows that both the active power $\mathrm{P}$ and the reactive power $\mathrm{Q}$ transmitted at one line end can be controlled.

The shunt converter operates as a STATCOM. In summary, the shunt converter controls the AC voltage at its terminals and the voltage of the DC bus. It uses a dual voltage regulation loop: an inner current control loop and an outer loop regulating AC and DC voltages. Control of the series branch is different from the SSSC. In a SSSC the two degrees of freedom of the series converter are used to control the DC voltage and the reactive power. In case of a UPFC [10] the two degrees of freedom are used to control the active power and the 
reactive power. The series converter can operate either in power flow control (automatic mode) or in manual voltage injection mode.

\section{SIMULATION RESULTS}

A Unified Power Flow Controller (UPFC) is used to control the power flow in a $120 \mathrm{kV} / 25 \mathrm{kV}$ transmission systems. The system connected in a loop configuration consists essentially of three buses (B575, B25, B120) interconnected through transmission line (L1) and two transformer banks. The model of DFIG based 9MW wind farm with UPFC is designed using MATLAB/ SIMULINK is shown in Fig.4.

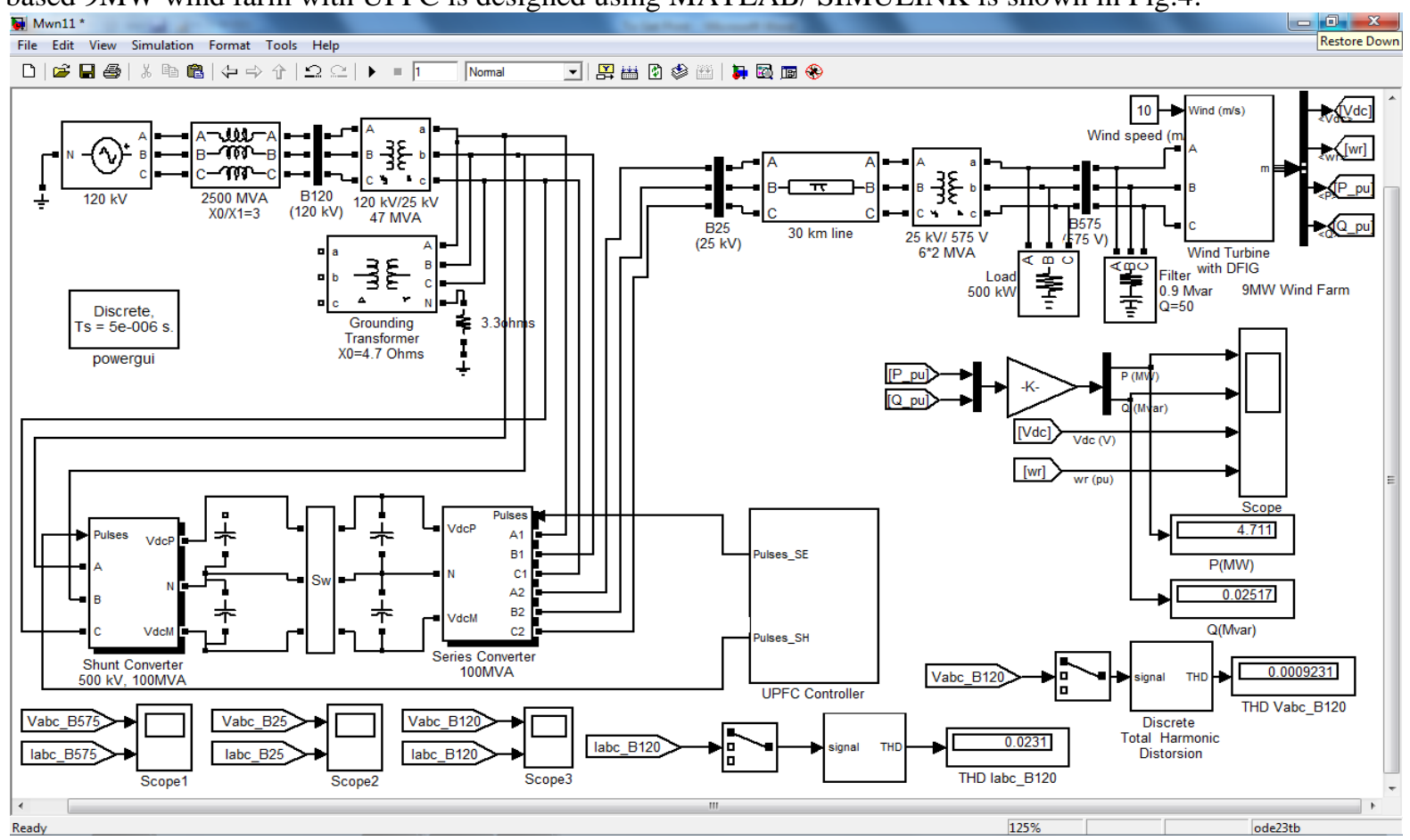

Fig.4 DFIG based wind energy conversion system with UPFC

The UPFC located at the right end of the $30-\mathrm{km}$ line $\mathrm{L} 1$ between the $120 \mathrm{kV}$ buses B25 and B120 is used to control the active and reactive powers flowing through bus B25, while controlling voltage at bus B120. The UPFC consists of two 100-MVA, three-level, 48-pulse GTO-based converters, one connected in shunt at bus B120 and one connected in series between buses B120 and B25. The shunt and series converters can exchange power through a DC bus.

The ideal switches and zig-zag phase shifting transformers are used to build a GTO-type 100 MVA, $138 \mathrm{kV}$ voltage source inverters which are used as shunt and series converters in the simulated model. This type of converter is used in high-power (up to 200 MVA) Flexible AC Transmission Systems (FACTS) which are used to control power flow on transmission grids. It can be used to build a model of shunt or series static compensator (STATCOM or SSSC) or, using two such converters, a combination of shunt and series devices known as Unified Power Flow Controller (UPFC).

This pair of converters can be operated in three modes:

- Unified Power Flow Controller (UPFC) mode, when the shunt and series converters are interconnected through the DC bus. When the disconnect switches between the DC buses of the shunt and series converter are opened, two additional modes are available.

- Shunt converter operating as a Static Synchronous Compensator (STATCOM) controlling voltage at bus B1

- Series converter operating as a Static Synchronous Series Capacitor (SSSC) controlling injected voltage, while keeping injected voltage in quadrature with current.

The wind turbine output active power is shown in Fig.5. The wind turbine reactive power is shown in Fig.6. 


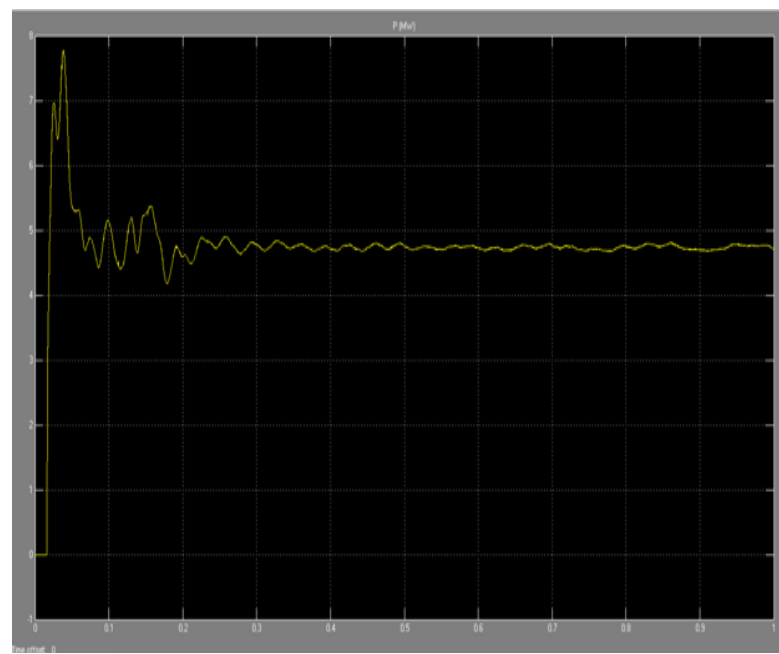

Fig.5 Wind turbine output active power (MW)

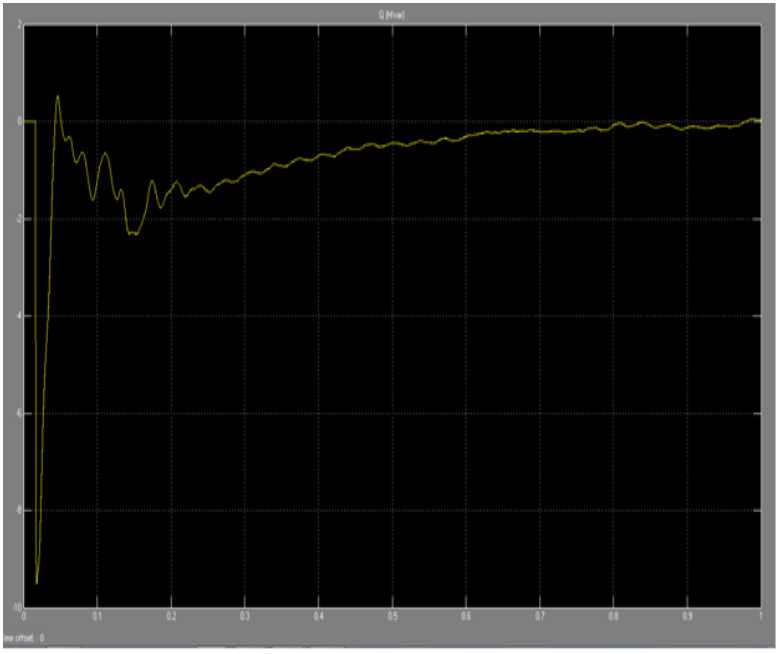

Fig.6 Wind turbine output reactive power (Mvar)

When the two converters are operated in UPFC [11] mode, the shunt converter operates as a STATCOM. It controls the bus B120 voltage by controlling the absorbed or generated reactive power while also allowing active power transfer to the series converter through the DC bus. The reactive power variation is obtained by varying the DC bus voltage. The DC link voltage is shown in Fig.7. The rotor speed is shown in Fig.8

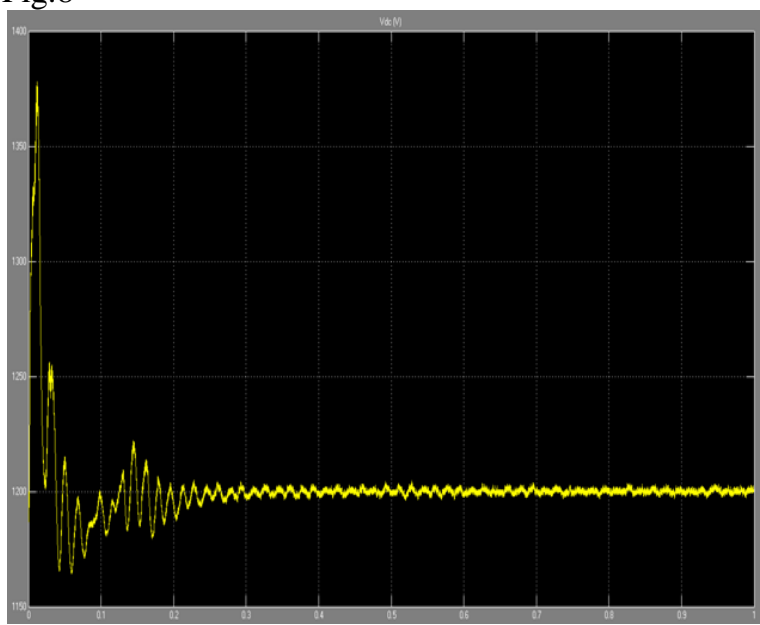

Fig.7 Dc link voltage (V)

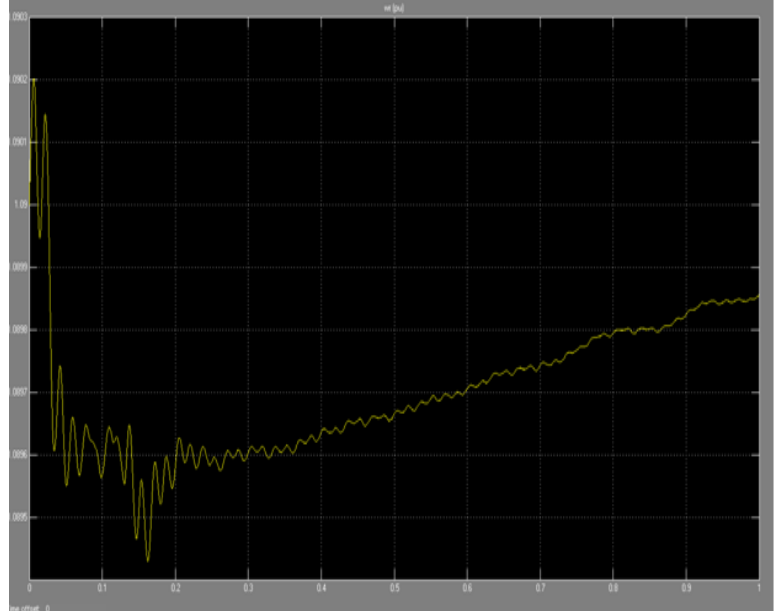

Fig.8 Rotor speed

The voltage (Vabc_25) and current (Iabc_25) at bus B25 without UPFC controller and with UPFC controller are shown in Fig.9 and Fig.10.

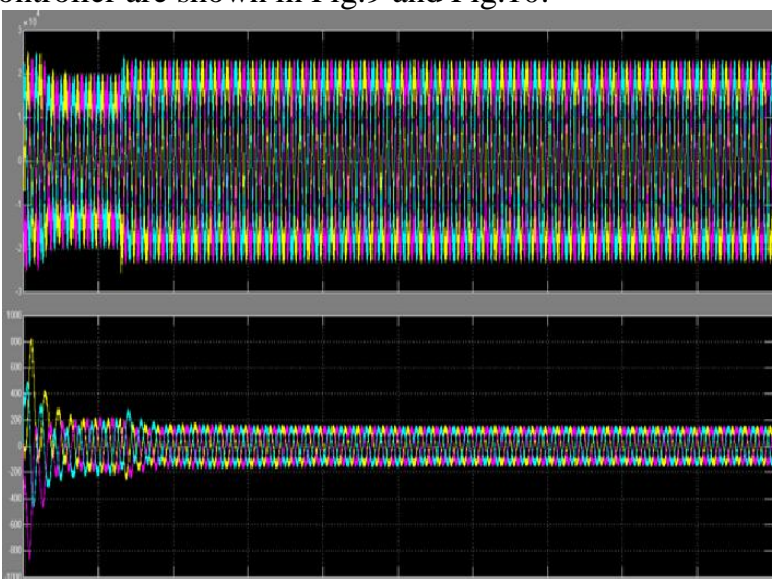

Fig.9 The voltage, current at bus B25 without UPFC

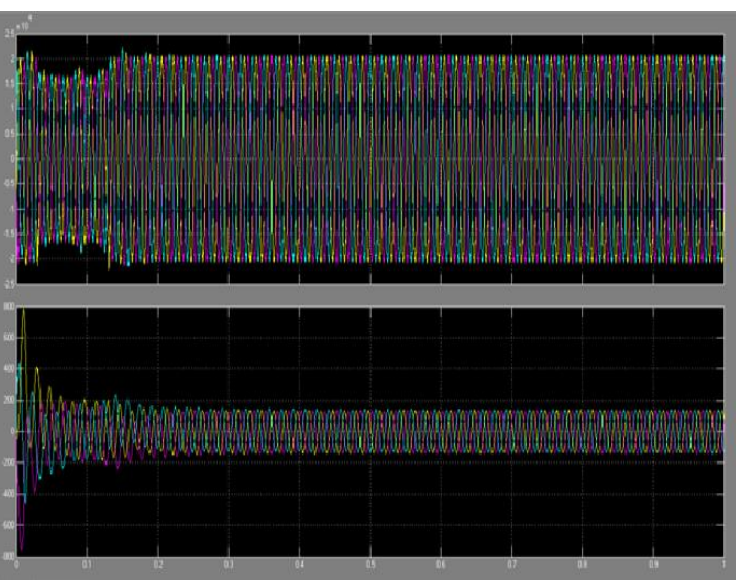

Fig.10 The voltage, curren at bus B25 with UPFC 
The power quality analysis in DFIG based wind energy conversion system is done by using the FFT tool of the powergui, you will find that decrease in the THD of the current injected in the system. The FFT of Iabc_25 without UPFC controller is shown in Fig.11. The FFT of Iabc_25 with UPFC controller is shown in Fig.12.

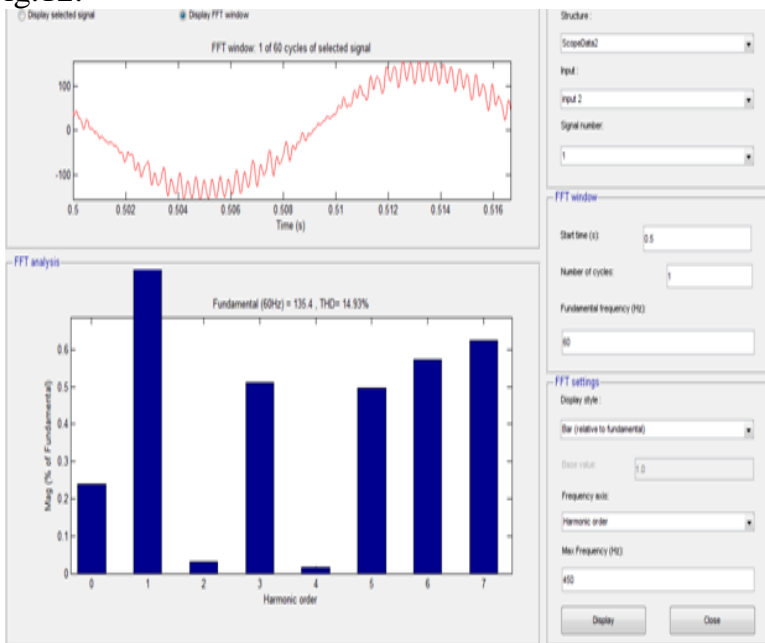

Fig.11 The FFT of Iabc_25 without UPFC controller

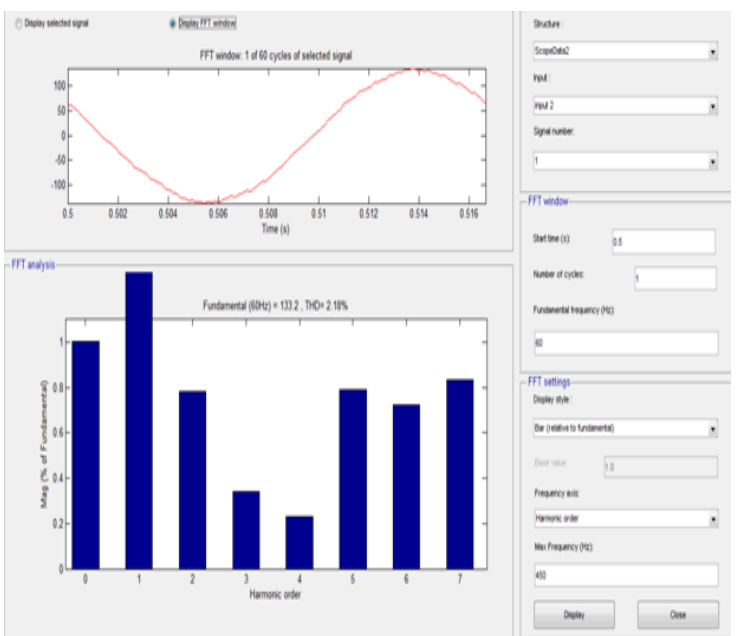

Fig.12 The FFT of Iabc_25 with UPFC controller

The FFT of Iabc_120 without UPFC is shown in Fig.13. The FFT of Iabc_120 with UPFC is shown in Fig.14.

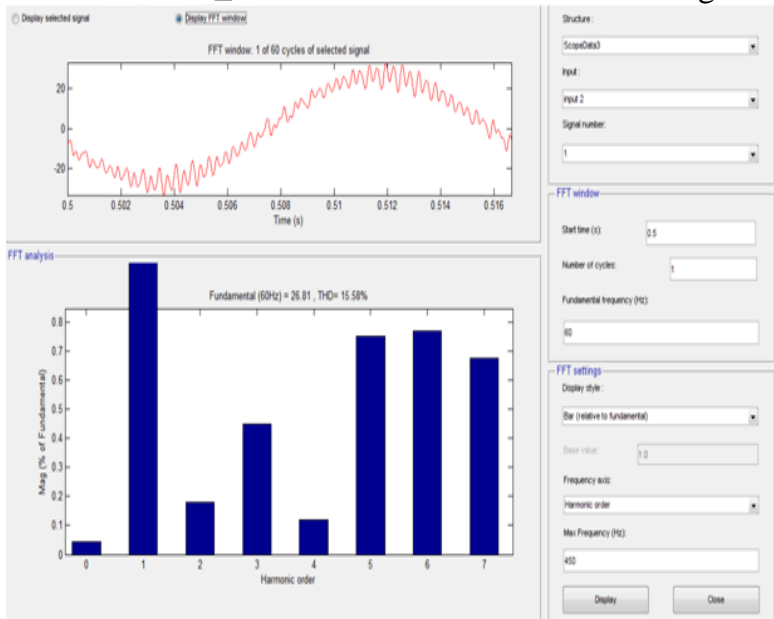

Fig.13The FFT of Iabc_120 without UPFC

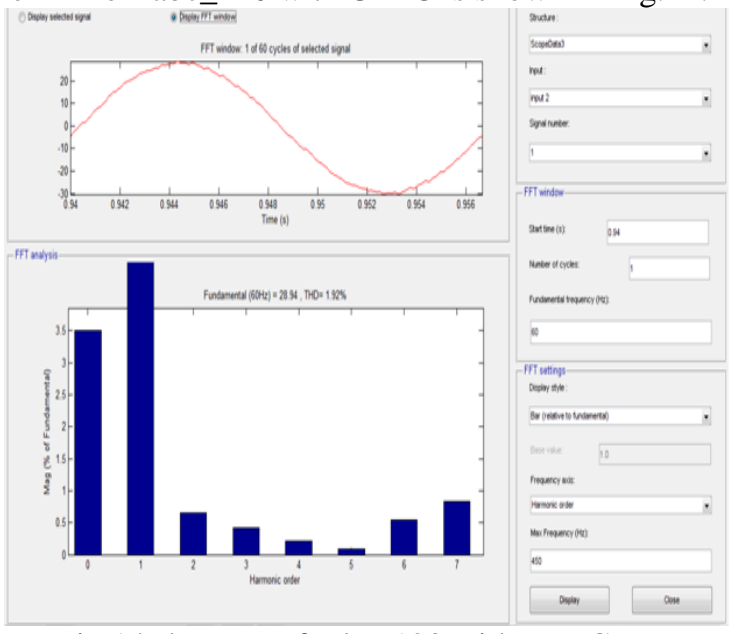

Fig.14The FFT of Iabc_120 with UPFC

The THD of voltage and current without and with UPFC controller are given in table.

TABLE I: THD OF V \& I WITHOUT AND WITH UPFC

\begin{tabular}{|c|c|c|c|c|}
\hline & \multicolumn{2}{|c|}{$\%$ THD in FFT Analysis } & \multicolumn{2}{|c}{$\begin{array}{r}\text { THD in Discrete Total Harmonic } \\
\text { Distortion block }\end{array}$} \\
& Without UPFC & With UPFC & Without UPFC & With UPFC \\
\cline { 2 - 5 } & $32.76 \%$ & $3.12 \%$ & 0.3183 & 0.03047 \\
Vabc_B575 & $14.05 \%$ & $1.77 \%$ & 0.1377 & 0.01755 \\
Iabc_B575 & $12.15 \%$ & $1.88 \%$ & 0.1192 & 0.01882 \\
Vabc_B25 & $14.93 \%$ & $1.90 \%$ & 0.1473 & 0.02254 \\
Iabc_B25 & $1.27 \%$ & $0.09 \%$ & 0.01252 & 0.0009158 \\
Vabc_B120 & $15.58 \%$ & $1.83 \%$ & 0.1566 & 0.02358 \\
Iabc_B120 & & & & \\
\hline
\end{tabular}


From all the previous figures, it can be observed that the UPFC controller mitigates the harmonic distortion that caused by the nonlinear load where all values of THD for voltage and current at all AC buses are decreased to values within allowable limits of IEEE standard.

\section{CONCLUSION}

In power system transmission it is desirable to maintain the voltage magnitude, phase angle and line impedance. Therefore, to control the power from one end to another end, this concept of power flow control and voltage injection is applied. Modeling the system and studying the results have given an indication that UPFC are very useful when it comes to organize and maintain power system. The UPFC is a device which can control simultaneously all three parameters of line power flow (line impedance, voltage and phase angle). The UPFC combines together the features of the Static Synchronous Compensator (STATCOM) and the Static Synchronous Series Compensator (SSSC). In practice, these two devices are two Voltage Source Inverters (VSI's) connected respectively in shunt with the transmission line through a shunt transformer and in series with the transmission line through a series transformer, connected to each other by a common dc link including a storage capacitor.

The shunt inverter is used for voltage regulation at the point of connection injecting an opportune reactive power flow into the line and to balance the real power flow exchanged between the series inverter and the transmission line. The series inverter can be used to control the real and reactive line power flow inserting an opportune voltage with controllable magnitude and phase in series with the transmission line. It was found that the UPFC [12] regulates the voltage of the bus as well as regulates the active and reactive power of the buses and the lines within specified limits. Therefore the UPFC can fulfill functions of reactive shunt compensation, active and reactive series compensation and phase shifting. The UPFC controller mitigates the harmonic distortion that caused by the nonlinear load where all values of THD for voltage and current at all AC buses are decreased to values within allowable limits of IEEE standard.

\section{REFERENCES}

[1]. J. G. Slootweg and W. L. Kling, Wind power in power systems, John Wiley and Sons, Ltd., 2005.

[2]. A. Morales and J.C. Maun: "Power quality responsibilities by grid impedance assessment at a wind power production", CIRED, Barcelona, Spain, 12-15 May 2003.

[3]. S. W. Mohod and M. V. Aware," Power quality issues \& its mitigation technique in wind energy conversion," in Proc. of IEEE Int. Conf. Quality Power \& Harmonic, Wollongong, Australia, 2008

[4]. Dr. Rakesh Saxena, Sonali Barod, "Analysis of power Quality in power Supplies", International Journal of Scientific \& Engineering Research Volume 3, Issue 8, August-2012

[5]. Power Quality issues standards and guide lines\|, IEEE, Vol-32, May96

[6]. N. G. Hingorani and L. Gyugyi, Understanding FACTS: Concepts and Technology of Flexible AC Transmission Systems, New York: IEEE, 2000.

[7]. A.P. Jayam, B.H. Chowdhury, "Improving the dynamic performance of wind farms with STATCOM", IEEE, 2009.

[8]. Daad-Saoud Z., "Application of STATCOMs to Wind Farms," IEE Proc. Gener. Transm.Distrib.Vol.145, No.5, pp.511-517, 1998.

[9]. F. Wang, "Design of SSSC Damping Controller to Improve Power System Oscillation Stability, "07803-5546-6/99/\$10.00 @ 1999 IEEE.

[10]. Gyugyi, L. "Unified power flow controller concept for flexible AC Transmission system", IEE Proceedings-C vol-139, no.4,pp 323-331 July 1992.

[11]. A.M Vural and M.Tumay, "Steady State Analysis of Unified Power flow controller: Mathematical Modeling and Simulation studies," in Proceedings of the IEEE Power tech Conference June 23-, Bologna, Italy. 2003.

[12]. Vibhor Gupta, "Study and Effects of UPFC and its Control System for Power Flow Control and Voltage Injection in a Power System," International Journal of Engineering Science and Technology Vol. 2(7), 2010. 